\title{
Analysis on Relationship between Pure Income Polarization and Economic Changes
}

\author{
Noraniza Yusoff \\ School of Government, UUM College of Law, Government and International Studies, 06010 UUM Sintok, Kedah Malaysia
}

\begin{abstract}
Polarization is examined from the viewpoint of clustering of peoples throughout local pillars and inside-cluster designation. The principal impact of the workforce position is greater essential than each of the other indicators in assessing dissimilarities in earning. Research on the matter of earning bipolarization is an essential aspect however ignored dimension of earning dispersion. The objective of this paper is to examine the relationship between pure income polarization and economic change. This research is an explanatory research using quantitative approach for primary data collection to explain the role of economic change to influence pure income polarization in the Northern Area of Peninsula Malaysia encompassing Sungai Petani, Northeast of Penang and Kinta, Perak. Survey using questionnaire were conducted on 434 respondents in the year 2016. Probability sampling technique utilized was a stratified sampling according to the race group of Malaysian citizens namely Malay Chinese and Indian. Questionnaire filled through self-administered and filled by researcher. Economic change through scatter plot shows no relationship with pure income polarization. However, through correlation analysis the two variables showed a moderate positive association.
\end{abstract}

Keywords: polarization, urbanization, economic changes, income

\section{Introduction}

Income equity could be inferred as an essential predictor of the economic force of every income category in the community. Throughout the year 1998 until 2013, the grow in income polarization and weaker marginal tendency to expenditure have eliminated the degree of actual utilization at the accumulative stage, by nearly $31 / 2$ percent - corresponds to more than one year of utilization [1]. [2] exhibited the probable negative socio-economic impacts of wage bipolarization are the major reason for this study on the factors of earning polarization. The research implemented multi-stage methods to examine for the factors of wage bipolarization at the family and the nation stage to a panel of approximately 300,000 families in European Union nations across the term of 2003-2009. From the policy related macro indicators, greater advancing worker taxing and to a specified degree capital taxing is positively associated with weaker degrees of earning polarization. Public spending on social security, education and economic funding are connected to a weaker level of polarization. Smaller jobless, a greater industrial foundation and business accessibility are also connected with weaker stages of bipolarization.

Polarization has been examined in a cross-section or time series context at the macro and micro stage differently; researcher concern in the problem of income bipolarization is connected to examining the factors of earning polarization at the micro-stage design over a set of micro-economic nation data collections. Wage bipolarization is the proportion of family income to the median earning of every nation and year in percentage scores. This sort of distribution assess was first employed for the purpose of explain at the total stage the ending of the middle stratum in the beginning of polarization discourse in the 1980s. In particular, no people have employed a multi-stage method to examine for the factors of wage bipolarization [2].

[3] employed the census public-usage microdata files
(PUMFs) to estimate indices of bipolarization across families, displaying that earning bipolarization across families enhanced, however these data create restrictions for assessments of earning disparities and bipolarization. The approach for generating the PUMFs has transformed across time, which possibly impact the findings available with the data. Polarization pertaining to a circumstance in which wage earners focuses toward two different clusters, one considerably great earning and one more considerably small wage. Suburban regions for example areas in York territory frequently comprise families in which there is one considerably high-wage earner, meanwhile other members of the family probably have smaller wages such as if a partner or adolescent member holds a part-time work. If these members are aggregated collectively, the finding is great stages of polarization between peoples.

Polarization is examined from the viewpoint of clustering of peoples throughout local pillars and inside-cluster designation. The principal impact of the workforce position is greater essential than each of the other indicators in assessing dissimilarities in earning. High-educated labors have opportunities of growing their wage throughout their job impacts by age [4]. [5] displayed in assessing earning bipolarization, investigators regard two notions, or axioms. Firstly is the diffuse axiom, which is that polarization rises at every time that the earning dispersion of the population changes from the median wage (for example, the diffuse broaden). To the beginning axiom is also commonly connected with rising disparities. The following is the bipolarization axiom in which polarization rises if the wage dispersion turns into centered toward two poles that do not cross the middle. The bipolarization axiom is fulfilled every time that the inhabitant becomes greater clustered toward these two poles, notwithstanding if this implies that the relatively poorest see their wage rise (however to a stage smaller than the average for the poor pole) or the richest consider their wages drop (however to a stage greater than the average for the rich pole). Note that the second case 


\section{International Journal of Science and Research (IJSR) \\ ISSN (Online): 2319-7064}

Index Copernicus Value (2015): 78.96 | Impact Factor (2015): 6.391

could indicate a circumstance in which polarization is raising, whereas disparity is declining.

[6] implies in the present thesis the researcher investigate dissimilar elements of convergence bipolarization, with focus nonlinear transport situation and complexities electrode increase. The researcher purpose at refining the vital attributes which feature the issues, and to that end the researcher apply a diverse of numerical and analyzing approaches. The previous research interests a basic issue in the research of focus bipolarization at excessive restricting present, specifically the emersion of a prolonged spacecharge area close the ion-selective interface.

\section{Literature Survey}

There are numerous investigators on income polarization such as [7] signified the matter of earning bipolarization is an essential aspect however ignored dimension of earning dispersion. Assessments of two criterions of wage bipolarization are acquired for the inhabitant, rural and urban industries utilizing family survey data on spending per capita for a sample of Asian nations. The results comprise the following: income bipolarization and disparities, the second assessed applying the Gini coefficient, are highly positively related; in the majority nations, urban wage bipolarization is greater than rural wage polarization; and the final, greater rates of increases in Gross Domestic Product (GDP) and per capita GDP, greater stages of educational achievement of family heads, and great rates of occupation in manufacturing probably pivotal in retaining earning bipolarization at poor stages.

[8] indicated that three notable empirical findings: actual personal leisure time as well as wage is a pivotal and considerable polarization characteristic. Remuneration is of economic and statistical significant. The recent minimum multidimensional polarization gap (2DGAP) method discovers that multidimensional polarization enhanced in the 1990s in Germany. [9] by examining the transition of the worldwide dispersion of technology abilities, researcher possibly therefore examine the extent to that technology as pivotal determinant to describe the pattern of growing wage bipolarization and emerging twin-peaks as well as identify the technology aspects that are more closely associated to the changes of GDP per capita. [10] signified that for rising value of $\alpha$, the Duclos-Esteban-Ray index (DER) focuses the rising significance of the creation of wage clusters in community.

Disintegration by cluster remarkably exhibit the disintegration of the DER index is largely more stabled. Earning polarization is moderately greater impacted by the inside aspects, the comparative influence of which (53.5 percent in 2006) proposes the occurrence of wage deviations in rural and urban regions. However, the non-trifling influence of among-cluster differences (46.5 percent in 2006) indicates that there are significance variations among rural and urban wage bipolarization. The growth in rural wage polarization is modest because the designation aspect has stagnated and even remarkably declined during the year
2000. The increase of rural bipolarization and inequity is closely connected to non agricultural chances in rural regions [10].

Polarization that articulates a recent viewpoint on the inequity discourse is an essential and different aspect of the dispersion of wage. During the year 2006-2010, a term that comprises a year instantly initial to and immediately following the downturn, there was a raise in wage bipolarization of nearly 1.4 percent (CAGR). However, the index fallen throughout the real downturn period (20072009) by remarkably greater than half a percent (CAGR). The researcher has no decisive description for the findings acquired. The researcher duty was a mostly explorative and restricted to generating the actual record of the effect of the downturn on wage polarization in the State of Connecticut Policy in Connecticut emerges to be centered on an inaccurate perception of a raise in wage bipolarization and the perception that the middle stratum share of the revenue distribution is decreasing. Generating the actual record in a statistically strong approach is essential for reconsidering present policy and creating next policy [11].

Income bipolarization declined from the 1980s earlier than rising at approximately the identical rate from the year 1990 forward. Analyses of wage polarization between peoples nevertheless discover that York area had the highest stage in every study year. Stage of wage bipolarization between peoples in the City of Toronto is mostly similar to those of the Toronto Census Metropolitan Area (CMA) as an overall and the City of Vancouver in every research year. Merely Montreal deviates moderately from these patterns, as its bipolarization stages have fully developed more gradually and periodically. In the year 2010, assessing people wages, York Region maintains a top status between other research locations, exceeded modestly merely by the City of Vancouver [3].

The earning dispersion created an establishment of two poles of wage, rich and poor, as well as a full depletion of the middle stratum. An assessment of the economic bipolarization displays raised values. The assessments of economic bipolarization are an option to the assessment of inequity [12].

In political discipline the first step for numerous quantitative researches of polarization is the strong examination of increasing proponent dissimilarities in roll-call electing action in Congress. The two-party alliances of the year 1950s and 1960s have conferred method to the party-line electing of the twenty-first century. However these patterns are manifest in simple descriptive statistics concerning proponent portion on roll calls, political scientists have formulated more clarified assessments of proponent electing dissimilarities Throughout the 1930s to the middle of $1970 \mathrm{~s}$, the assessments of proponent bipolarization by calculating the dissimilar in means (or medians) throughout the political parties was considerably small [13].

[14] indicated that nearly the whole of the bipolarization impact came from goods desire changes throughout activities that have raised the comparative need for high-and low- 


\section{International Journal of Science and Research (IJSR) \\ ISSN (Online): 2319-7064}

Index Copernicus Value (2015): 78.96 | Impact Factor (2015): 6.391

skilled employees at the expenditure of middle-skilled employees, strengthening polarization of the occupation and earning arrangements in Egypt. Whereas raised rivalry from imports had a contrary effect for middle-skilled labors, growing of the private sector has produced opportunity to raise desire for the whole skills mostly those of the middle skills, lessening the level of bipolarization across time. Demand-driven bipolarization in Egypt has three policy impacts consists of capitalizing in human capital by increasing the quality of education and training arrangements would enable labors to obtain the types of skills that are in higher desire in the worker market, grow their yields and raise their upcoming incomes; growing private sector involvement in economic activity by benefiting a transparent commercial conditions and a more adjustable worker market would circulate need for the whole skills, mostly those of the middle skills; and improving goods in not fully developed activities and capitalizing in activities with great work content of development would assist promote the desire for their goods and circulate occupation, subsequently constricting income inequality throughout activities.

The level of spatial bipolarization is assessed reference to the share of inequity constituted by the among cluster aspect. The option of the segmentation can basically shift any disparities assessment disintegration, both qualitatively and quantitatively. For the purpose of resolving this issue the investigator suggests an essence method to the spatial polarization assessment relied on the Theil index calculated on the spatial in motion means. This enables to discover a bipolarization curve assessing the level of geographic convergence reference to a role of a spatial measure parametric quantity, signifying the geographic aspect of the clusters. The analyses of per capita earning data of the Italian regions in 20th century reveals the occurrence of a various polarization in other words per capita wage is bipolar at dissimilar spatial measure. The analysis also exhibits the occurrence of a prolonged geographic guild concentration with concentrating guilds and a reinforcing of the bipolarization, principally imputable to territorial dissimilarities; the strengthening of North-South duality is more constrained [15].

\section{Methodology}

\subsection{Problem Definition}

Gripping prove is continual deficient and necessarily to be accumulated. Initially, there has been a considerable transformation in worldwide urbanization stages and economic growth throughout the past 30 years. This produces a natural checkpoint for validating whether the present empirical data advocate the recent viewpoint. Subsequently, inside the scope of globalization, majority nations are profoundly incorporated inside global arrangements. Consequently, it is preferable to analyze the transforming worldwide trend entirely. Internationally, the urbanization stage has increased from 39 percent in the year 1980 to 52 percent in the year 2011. Nevertheless, the total comparative stage of dispersion of urbanization on a national scale global is fundamentally consistent across the time span. The advanced areas for example North America, Europe and Australia continue at a greater stage of urbanization whereas the growing nations are comparatively smaller [16].

Bipolarization or polarization [10] refers to the actual fact to a position that exist significance amount of peoples that are most poor however there occurs also a non-trifling share of the inhabitant that is quite rich. Implied a disparity among the "poor" and the "rich" infers apparently that there is no considerable middle stratum. The assessment of polarization is subsequently connected to that of the significant of the middle stratum. The issue of bipolarization turns into even more connected promptly an individual agrees the notion that the total wage dispersion is in reality a combination of numerous dispersions. The concept of polarization emphasizes in the two ideas namely raising spread and enhanced bipolarity [17].

\subsection{Research Design}

This research is an explanatory research using quantitative approach for primary data collection to explain the role of economic change to influence pure income polarization in the Northern Area of Peninsula Malaysia encompassing Sungai Petani, Northeast of Penang and Kinta, Perak. Survey using questionnaire were conducted on 434 respondents in the year 2016. Probability sampling technique utilized was a stratified sampling according to the race group of Malaysian citizens namely Malay, Chinese and Indian. Questionnaire filled through self-administered and filled by researcher. Data analysis involved correlation and scatter plot. The objective of this paper is to examine the relationship between pure income polarization and economic change. Independent variable is economic change and dependent variable is pure income polarization. The research question is why pure income polarization related with economic change? The research Null hypothesis is there is no relationship between pure income polarization and economic change. Figure 1 show the relationship between variables.

\begin{tabular}{|l|l|}
\hline $\begin{array}{l}\text { Economic } \\
\text { change }\end{array}$ & $\longrightarrow \begin{array}{l}\text { Pure income } \\
\text { polarization }\end{array}$ \\
\cline { 2 - 3 }
\end{tabular}

Figure 1: The relationship between independent (economic change) and dependent variables (pure income polarization)

\subsection{Data Collection and Analysis}

This research is a basic research and the purpose of the study is to explain on the relationship between economic change and pure income polarization. Time dimension of the research is cross-sectional. Quantitative approach utilized in this research for data collection and analysis. Data collected through survey using questionnaire at Sungai Petani, Kedah; Georgetown, Penang and Ipoh, Perak. Data collected on 12 August 2016 until 30 September 2016 at the research location area. Whereas data collection through telephone 4 August 2016 until 14 December 2016.

\section{Results and Discussion}

Scatter plot display that no correlation $\left(r_{\mathrm{s}}=0\right)$ between pure 


\section{International Journal of Science and Research (IJSR) \\ ISSN (Online): 2319-7064}

Index Copernicus Value (2015): 78.96 | Impact Factor (2015): 6.391

income polarization and economic change. Thus the value of $r_{s}=0$ imply there is no relationship between the variables [18]. The correlation coefficient through Spearman correlation analysis of economic change and pure income polarization is $\mathrm{r}=0.619^{* *}, \mathrm{p}=0.000(\mathrm{p}<0.01)$ and $n=434$ shows a significant correlation. Economic changes and pure income polarization have a high positive correlation. Thus, the Null hypothesis successfully denied that there was a significant relationship between economic change and pure income polarization.

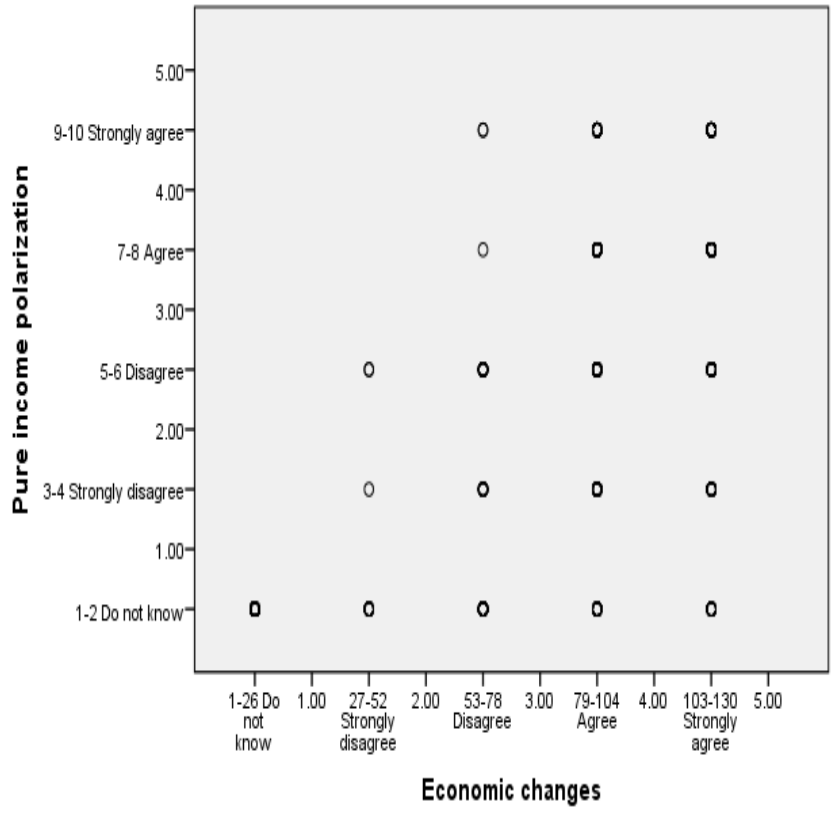

There is a relationship between economic change and pure income polarization. The $r$ value indicated moderate positive correlation. The relationship between economic change and pure income polarization is at a moderate level. The higher the economic change the higher the pure income polarization will be create. If economic change increases, pure income polarization will increase. Ho: $\mathrm{p}=0.000$, the economic change and pure income polarization correlation coefficient is 0.619 ; there is association between the economic change and pure income polarization.

This finding corresponding with research by [19] that analyzes the correlation among wage bipolarization and economic development in the areas of the European Union throughout the period 1993-2003. The findings imply that the stage of earning bipolarization is negatively connected with regional development. The result is in reality strong to numerous option stipulations consists of an amount of supplemental explanatory variables for instance prior per capita gross domestic product, industry combination, human capital stock, inhabitant concentration or market possibility. Moreover it should be recognized that the measured negative association among polarization and economic achievement does not rely on the amount of clusters utilized to examine the level of wage classification throughout the sample areas.

Cities are undergoing considerable tension to reduce the risks from bipolarization of economic possibility among and inside cities. Growing rivalry among cities and areas to invite commercial, especially in Europe, has made it important for cities to supply corporations with a propitious facilities design. Enlarging national and international transport facility as well as enhancing the achievement of education and academic study is completely vital [20].

However, the finding different with study by [21], that examination represents none proof for individualization or stratum bipolarization of danger. Alternatively, while economic tension stage is highly classified in stratum regards in growth and recession terms, the shifting effect of stratum is highly possible on way of life phase. An earning centered on categorization indicated that the rich earning stratum encountered its benefit comparative to the earning poor stratum decrease at the initial phase of the way of life and continue balanced throughout the remain of the way of life. The structure of the earning poor stratum encountered a comparative progress in their condition in the previous way of life stage and not significance transformation at the second phases. For the remaining earning stratums, way of life phase was certainly more pivotal. At the previous phase the dangerous stratum encountered different advancement in its situation whereas the results for the middle stratums continue static. In the middle way of life the dangerous and lower middle stratums encountered unequal raise in their tension stages whereas at the second phase it is the integrated middle stratums that not profit. Supplementary impacts across time concerning to social stratum are limited to the declining condition of the small bourgeoisie at the middle phase of the way of life.

The result corresponding with the inference by [22] that scientific and technological transformation from the encouraging force of scientific and economic policies accepted to determine economic growing and progress. Technological advancement contributes economic expansion. Nevertheless, it also raises social affluence from one point of view by raising the earning stages and affluence produces specific social issues as another point of view. The fluctuations and uncertainties formed in the business life by the technological growth generated uncertainties in the job levels of the workers. Whereas technological growth removed particular employments and occupations regions in addition to made a negative effect to job from one point of view, it formed recent employment chances and educated other approaches to execute the occupations from another point of view. The situations created negative implications for the growing nations that have large problems in generating technology. The traditional industrial centers of the previous discover difficult to maintain their rivalry force and concurrently, worldwide cities initiated to turn into influential as recent supervising centers. Producing raised communication, easy and quick admittance to the recent markets, rise in the marketing mechanisms and corporation unions, technological progress result a positive effect to the economy. As a consequence of e-commerce resulted on Internet, the aspects of business have transformed. The providers and customers could fulfill with one another in global markets via e-commerce and produce business Technological increases grow rivalry between countries. 


\section{International Journal of Science and Research (IJSR) \\ ISSN (Online): 2319-7064}

Index Copernicus Value (2015): 78.96 Impact Factor (2015): 6.391

\section{Conclusion}

Economic change through scatter plot shows no relationship with pure income polarization. However, through correlation analysis the two variables showed a moderate positive association. Increasing in economic change will raise pure income polarization. The higher economic change, the higher pure income polarization will occur. Implication of this research may apply the views expressed by [23] that concluded common policies planned to incorporate to the global possibly are not optimum for economic development by itself. Economic globalization not specifically encourages development however also obliquely does exactly through complementary regenerates. The policy effects of this research are directly. Incorporating to the worldwide economy is merely one portion of the record. The other is the way to greater profit from globalization. In this regard, the obligation of policy makers is to enhance the stage of educated employees and reinforce of monetary arrangements to obtain greater opportunists from globalization. These economic policies are essential not merely in the people right, however also in assisting growing nations to obtain the profits of globalization. Nevertheless, execution of recent technologies distributed from developed economies needs skilled employees. The researcher findings proposed that the vital of growing educated labors as a complementary policy in developing globalization. In reality, nations with greater stage of human capital can improving and rapidly replicate as well as enforce the distributed technologies. The successfully incorporated over nations. This signifies the vital of human capital in the victory of nations in the globalizing worldwide. Monetary generous in the pattern of Foreign Direct Investment carry the knowledge and administrative for adopting the recent technology. It is possibly useful in improving the stage of human capital in host nations. Nevertheless, robust and well-functional monetary arrangements possibly contribute the influx of foreign capital to the generative and suitable sectors in Organization of Islamic Cooperation.

\section{Future Scope}

Future studies can focus on peoples background differences with occurrence of income polarizations. [1] suggested income polarization of women as an interesting question for future research to study.

\section{Acknowledgement}

This research is Fundamental Research Grant Scheme (FRGS) Research grant. ISO No. 13228.

\section{References}

[1] A. Alichi, K. Kantenga and J. Sole, "Income polarization in the United States," In International Monetary Fund Working Paper WP/16/121, pp. 1-26, 2016.

[2] M. Holzner, "The determinants of income polarization on the household and country level across the EU," In
Wiener Institut fur Internationale Wirtschaftsvergleiche Working Paper 93, pp. 1-31, 2012.

[3] A. Walks, M. Dinca-Panaitescu and D. Simone, "Income inequality and polarization in the City of Toronto and York Region Part I: examining levels and trends from spatial and non-spatial perspectives," Neighborhood Change Research partnership, pp. 1-47, 2016.

[4] M. Mussini, "On measuring income polarization: an approach based on regression trees," Statistics in Transition, 17(2), pp. 221-236, 2016.

[5] M. Dinca-Panaitescu and A. Walks, Income inequality, income polarization, and poverty: how are they different? How are they measured? Neighborhood Change Research Partnership, University of Toronto, 2015.

[6] C. P. Nielsen, "Concentration polarization: electrodeposition and transport phenomena at overlimiting current," DTU Orbit-The Research Information System Annual Report, 2015.

[7] M. S. Gochoco-Bautista, C. C. Bautista, D. S. Maliqaliq and N. R. Sotocinal, "Income polarization in Asia," Asian Economic Papers, 12(2), pp. 101-136, 2013.

[8] J. Merz and B. Scherg, "Polarization of time and income - A multidimensional analysis for Germany," In J. A. Bishop and J. G. Rodriguez, Economic well-being and inequality: papers from the Fifth ECINEQ meeting, 22, pp. 273-321, 2014.

[9] F. Castellacci, "Closing the technology gap?," In DIME Final Conference, pp. 1-34 , 2011.

[10] C. Bonnefond and M. Clement, "An analysis of income polarization in rural and urban China," 2017. [Online]. Available:

http://cerdi.org/uploads/sfCmsContent/html/367/Bonnef ond-Clement.pdf. [Accessed: June 6, 2017].

[11] A. E. Rodriguez and S. J. Scott, "Income polarization and income inequality in Connecticut during the Great Recession," International Journal of Arts and Commerce, 2(1), pp. 113-126, 2013.

[12] L. Pietak, "Economic polarization across European Union regions in the years 2007-2012 at nuts 2 level,'Folia Oeconomica Stetinensia, Doi: 10.1515/foli2016-0030, 2016.

[13] M. Barber and N. McCarty, "Causes and consequences of polarization," 2017. [Online]. Available: http://www.apsanet.org/portals/54/Files/Task\%20Force $\% 20$ Reports/Chapter2Mansbridge.pdf. [Accessed: June 7, 2017]

[14] O. Helmy, "Skill demand polarization in Egypt," Middle East Development Journal, 7(1), pp. 26-48, 2015.

[15] S. Iezzi, "The geographical polarization of per capita output: an analysis of the Italian case based on provincial data," In Bank of Italy, Economic Research and International Relations Area working papers, pp. 638, 2006.

[16] M. Chen, H. Zhang, W. Liu and W. Zhang, "The global pattern of urbanization and economic growth: evidence from the last three decades," PLOSOne, August, 2014 Doi: doi.org/10.1371/journal.pone.0103799, 2014. 
[17] J. Deutsch, A. Fusco and J. Silber, "The BIP trilogy (bipolarization, inequality and polarization", 7, pp. 2013-2022, 2013.

[18] Kent State University, "SPSS tutorials: Pearson correlation," 2017. [Online]. Available: http://libguides.library.kent.edu/SPSS/PearsonCorr. [Accessed: July 11, 2017].

[19] R. Ezcurra, "Does income polarization affect economic growth? The case of the European regions," Journal of Regional Studies, 43(2), pp. 267-285, 2009.

[20] M. Gornig, "Polarization of economic potential - the impact of tertiarization and Europeanization on cities," 2017. [Online]. Available: https://difu.de/publikationen/polarization-of-economicpotential-the-impact-of.html. [Accessed: June 8, 2017].

[21] C. T. Whelan, H. Russell and B. Maitre, "Economic stress and the Great Recession in Ireland: polarization, individualization or "Middle Class Squeeze"? 2016. [Online]. Availabe: https://www.esri.ie/publications/economic-stress-andthe-great-recession-in-ireland-polarizationindividualization-or-middle-class-squeeze/. [Accessed: June 8, 2017].

[22] H. K. Caliskan, "Technological change and economic growth," Procedia - Social and Behavioral Sciences, 195, pp. 649-654, 2015.

[23] P. Samimi and H. S. Jenatabadi, "Globalization and economic growth: empirical evidence on the role of complementarities," PLOSOne, August, 2014. Doi: doi.org/10.1371/journal.pone.0087824.

\section{Author Profile}

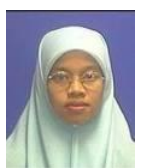

Noraniza Yusoff received the B.A. and M.A. Ph.D degrees in geography from University Malaya Kuala Lumpur in 1998 and National University of Malaysia in 1999, respectively. She received Ph.D degree from University Malaya Kuala Lumpur in 2015. She now with Universiti Utara Malaysia as a lecturer and worked as a lecturer since 2000 . 